\title{
Da anorexia histérica
}

\section{Charles Lasègue ${ }^{1}$}

Tenho o sentimento de que não se conseguirá constituir a história das afecções histéricas senão pelo estudo em separado de cada um dos grupos sintomáticos; somente após esse trabalho prévio de análise, poderse-á reunir os fragmentos e recompor o todo da doença. Considerada em seu conjunto, a histeria apresenta uma quantidade excessiva de fenômenos individuais e incidentes aleatórios, para que o particular possa ser apreendido no geral.

Esse procedimento, mais do que questionável se aplicado a doenças limitadas em termos de tempo, de espaço e localizações e de modalidades dos fenômenos, encontra um uso legítimo nesse caso. Busquei mostrar as características da tosse e da catalepsia passageira de natureza histérica; outros dedicaram preciosas monografias às hemiplegias, às contraturas transitórias ou duráveis, à anestesia etc. Hoje, meu objetivo é o de tratar de um complexus sintomático observado com uma freqüência que faz dele mais do que um acidente excepcional e que, além do mais, oferece a vantagem de nos fazer penetrar na intimidade das disposições mentais das histéricas.

Muitos distúrbios digestivos podem surgir no curso da histeria. Eles consistem em vômitos repetidos e às vezes incoercíveis, dores gástricas, hematêmeses, constipações ou diarréias singulares, quer por sua evolução, quer por algumas de suas características.

Entre os sintomas graves, os vômitos de sangue têm merecido uma atenção particular dos médicos; as gastralgias, fenômenos puramente subjetivos, não são bem conhecidas e os distúrbios intestinais deixam margem a mais incertezas ainda.

1. Tradução de Alain François e revisão técnica de Mário Eduardo Costa Pereira. 
Até então, deu-se preferência às perversões bizarras do apetite, cujos exemplos são abundantes e cujas variedades seriam quase incontáveis. Ao narrar fatos singulares, casos de apetências estranhas, negligenciou-se o estudo do estado verdadeiro das doentes e tudo acabou se reduzindo à noção improdutiva de que as histéricas são sujeitas às mais inverossímeis desordens das funções digestivas. Entretanto, não seria impossível tentar uma classificação desses tipos de anomalias. Contudo, embora houvesse tido a oportunidade de observá-las em grande número, não quero aqui falar delas, nem mesmo de passagem.

O objetivo desta dissertação é o de apresentar uma das formas da histeria com foco gástrico, bastante freqüente para que sua descrição não caia, como acontece com muita facilidade, numa generalização artificial de um caso particular, por um lado e, por outro, suficientemente constante em seus sintomas para que os médicos que já a observaram possam controlar a exatidão de minha exposição e quem, por acaso, a encontrar em sua prática não se sinta desprevenido. O termo anorexia poderia ter sido substituído pelo de inanição histérica, que talvez representasse melhor a parte visível dos acidentes. Preferi, sem defendê-la de alguma forma, a primeira denominação, exatamente por ela remeter a uma fenomenologia menos superficial, mais delicada como também mais médica.

Entre os vários tempos que compõem a digestão, o que é melhor analisado pelos pacientes e menos facilmente estudado pelos médicos é, com certeza, o apetite pela alimentação ou pelo alimento. Embora o termo anorexia seja geralmente adotado para representar um estado patológico, ele não tem correspondente fisiológico, uma vez que a palavra orexia não existe em nossa língua. Disso resulta que nos faltam expressões para designar os graus ou variedades de inapetência. Aqui, como em muitas partes, a pobreza do vocabulário reflete a insuficiência do conhecimento.

Em certos casos, o apetite desaparece sem que o paciente sinta quaisquer sensações que não uma queixa da falta de um excitante que o convide a se alimentar. Isso não acarreta qualquer repugnância e, via de regra, o provérbio que reza que l'appétit vient en mangeant ${ }^{2}$ encontra-se plenamente justificado.

Em outras condições, contudo, o paciente sente uma repulsão mais ou menos viva por certos alimentos; em outras ainda, qualquer substância que for, provoca aversão. Por mais geral que seja, a inapetência sempre respeita uma escala graduada e os alimentos não são indistintamente repelidos com a mesma insistência.

Em compensação, existem afecções, quer do estômago, quer do sistema nervoso central, localizadas ou diatésicas, acompanhadas por uma sensação apetitiva ilusória, que pode surgir em intervalos desiguais ou quase regulares. 
Esses falsos apetites exigentes, imperiosos, num grau só encontrado em certos diabéticos, foram observados em algumas histéricas. Quase sempre os doentes, obedecendo a uma hipótese teórica, assumem que seu mal-estar se deve à inanição e que conseguirão conjurá-lo com a ajuda de alimentos, por mais reduzidos que estes sejam. A experiência mostra que duas gotas de láudano têm mais eficiência para acalmar essa fome imaginária do que a ingestão de comida.

À sensação exagerada de apetite, à suposição que alimentos acalmarão a necessidade, correspondem, em sentido inverso, um apetite diminuto e a convicção de que a alimentação será prejudicial. O paciente age, então, como no primeiro caso, segundo uma hipótese instintiva. Dócil, desejoso de se livrar de seu receio, ele se esforçará e acabará se convencendo de que sua saúde sairá ganhando se continuar sua alimentação, mesmo ao preço de sofrimentos, que suas apreensões não tinham fundamentos. Se, ao contrário, for indócil, preocupado apenas por evitar uma dor hipotética, embora temida de antemão, ele insistirá em seu comportamento e se absterá de comer. Esse é o caso das histéricas cujo histórico vou tentar retraçar. Observações feitas durante anos não podem ser narradas e acho melhor, em vez de fatos particulares, apresentar um quadro, por assim dizer, esquemático da doença.

Uma moça entre 15 e 20 anos sente uma emoção que pode confessar ou dissimular. Na maioria dos casos, trata-se de um projeto real ou imaginário de casamento, de uma contrariedade no tocante a certa simpatia ou até mesmo de alguma aspiração mais ou menos consciente. Outras vezes, somos reduzidos a conjecturas quanto à causa real, quer porque a moça tem interesse em se fechar no mutismo tão comum às histéricas, quer porque, na verdade, a causa primária não está ao seu alcance. E veremos que entre essas múltiplas causas, várias podem passar despercebidas.

Ela começa por sentir um mal-estar subseqüente à alimentação: sensações vagas de plenitude, de angústia, de gastralgia, post prandium ou, melhor, desde o início da refeição. Nem ela nem as pessoas presentes vêem esse mal-estar como algo de importante e dele não resulta nenhum incômodo durável.

No dia seguinte, a mesma sensação se repete e continua insignificante, embora tenaz, por vários dias. A doente chega à conclusão de que o melhor remédio para esse mal-estar indefinido, particularmente penoso, consiste em diminuir sua alimentação. Até aí, nada de extraordinário: nenhum gastrálgico deixou de sucumbir a essa tentação até o momento em que adquire a certeza de que a inanição relativa não lhe traz benefícios, como também agrava seus sofrimentos. Na histérica, as coisas ocorrem de outro modo. Aos poucos, ela reduz sua alimentação, sob pretexto ora de uma dor de cabeça, ora de uma aversão momentânea, ora ainda do receio de ver as impressões dolorosas que 
sucedem às refeições se repetirem. Passadas algumas semanas, não são mais repugnâncias supostamente passageiras, mas uma recusa da alimentação que será prolongada por tempo indefinido. A doença declarou-se e vai seguir seu curso de modo tão fatal que fica fácil prognosticar o futuro.

Ai do médico que, por desconhecer o perigo, trata essa obstinação como fantasia sem importância, como que passageira, e espera vencê-la por meio de remédios, de conselhos amigáveis, ou pelo recurso ainda mais falho da intimidação! Com as histéricas, não há como consertar um erro médico inicial. À espreita dos julgamentos que se tem delas, especialmente dos que envolvem a família, elas não têm perdão e, quando consideram que as hostilidades começaram, sentem-se no direito de continuá-las com uma tenacidade implacável. Nesse estágio inicial, a única conduta sensata é a de observar, de se calar e de lembrar que, quando a inanição voluntária já dura várias semanas, ela já se tornou um estado patológico a longo prazo.

Importa, para avaliar a seu justo valor os diversos elementos que concorrem para a eclosão dessa doença, submeter cada qual a uma análise minuciosa.

A dor gástrica que é, ou parece ser o ponto de partida dos acidentes, merece especialmente que nos detenhamos nela. Ela varia em intensidade, desde um sentimento confuso de opressão até uma espécie de cãibra estomacal acompanhada por fraqueza, palidez, suores ou mesmo calafrios; nenhum vômito ou vontade real de vomitar, nem mesmo nos casos extremos; a doente apenas afirma que um grau a mais provocaria vômitos.

Se nos limitarmos às aparências, as crises de dores em nada diferem daquelas que observamos com muita freqüência em todas as afeç̧ões das vias digestivas. Elas são determinadas pela alimentação e não ocorrem entre as refeições. Se fosse assim, faltar-nos-iam sinais distintivos e estaríamos reduzidos a acrescentar a gastralgia à lista já longa das neuroses histéricas localizadas.

A sensação dolorosa não existe apenas por causa da comida, mas persiste mais ou menos viva no intervalo entre as refeições, ora insignificante, ora mais incômoda, e às vezes de modo tão diminuto que a doente se queixa de um malestar geral sem conseguir atribuir-lhe um ponto fixo. Independente de sua forma, sede e intensidade, será a sensação penosa causada por uma lesão estomacal ou, antes, a expressão reflexa de uma perversão do sistema nervoso central? Não creio que haja dúvidas para quem chegou a se colocar a questão.

Encontramos no início de um grande número de doenças cérebro-espinais, a angústia precordial, o sentimento de opressão, de contração epigástrica que sucedem até a emoções fugazes. Todos nós, ao sentirmos essa espécie de ansiedade, somos remetidos à causa moral que a produziu. Suponhamos, pelo contrário, um indivíduo subitamente acometido por uma constrição epigástrica surgida sem motivo aparente e cujo mal-estar chegue a despertar inquietação. O 
paciente se indaga a respeito da possível origem dessa estranha impressão e esse tipo de busca é, via de regra, o que dá inicio aos delírios de perseguição. Supondo que a afecção encefálica não leve a conseqüências tão graves, a primeira hipótese do paciente, e a mais natural, é a de que sofre de uma doença do estômago. Qualquer ansiedade epigástrica com apreensão, a meia-vertigem que a acompanha é aumentada pela alimentação: mais um motivo para acreditarmos na existência de uma irritação gástrica.

As características dessa gastralgia de causa reflexa não são impossíveis de discernir, embora as circunstâncias em que ela pode ser observada sejam muito raras.

Ela se distingue das irritações dolorosas do estômago: de fato, ela não tem uma localização exata e é completada por uma inquietação muito especial, por ser repentina e não ser prenunciada por distúrbios gradualmente crescentes da digestão. Ela também não é seguida por acidentes dispépticos, uma vez que as funções intestinais permanecem intactas, fora uma constipação persistente, embora fácil de vencer, pelo fato das crises não serem influenciadas pela natureza dos alimentos. E finalmente porque a modalidade da dor, quando de fato existe, não tem analogia com os sofrimentos gástricos ocasionados por uma lesão, por mais superficial que esta seja.

Uma vez determinada a natureza do mal-estar, temos progredido muito em direção ao diagnóstico. Nunca insistirei o bastante nessas neuroses dos órgãos esplâncnicos e suas relações com certos estados cerebrais.

A histérica, após um curto período de hesitação, acaba se convencendo de que a única chance de alívio que lhe é garantida reside na abstenção de alimentos. É fato que os remédios apropriados às outras gastralgias são absolutamente ineficientes, por mais zelo que médico e paciente coloquem em seu uso. Uma razão de outra ordem, dessas que sempre desempenham um papel preponderante na histeria, também intervém. A doente perdeu a sensação de apetite e seria preciso, para que consentisse em se alimentar, que vencesse seu temor da dor e não que a apetência por comida a solicite ou mesmo encoraje a isso; ao se abster, ela satisfaz, pelo contrário, duas inclinações ao mesmo tempo. Todas as manifestações histéricas, se é que havia alguma, ficam suspensas a partir dessa primeira fase. A doente, longe de enfraquecer, de entristecer-se, desenvolve uma espécie de alacridade que não lhe era costumeira: um pouco como se tomasse precauções para os períodos ulteriores e preparasse argumentos aos quais não deixará de recorrer.

A repugnância em se alimentar segue devagar seu curso progressivo. As refeições são cada vez mais reduzidas e uma delas apenas, almoço ou jantar, pode ser considerada como alimentícia. Quase sempre a paciente suprime sucessivamente um dos tipos de comida, o pão, a carne, certos legumes. Às 
vezes ela consente em substituir um alimento por outro ao qual se apega com uma predileção exclusiva por várias semanas, o pão, por exemplo, por torradas ou bolachas, para em seguida renunciar e substituir ou não os alimentos provisoriamente adotados.

As coisas prolongam-se assim durante semanas e meses, sem que a saúde geral pareça desfavoravelmente influenciada, a língua permanece clara e fresca, a sede nula. A constipação persistente não resiste a laxativos leves, a barriga não se retrai, o sono continua mais ou menos regular. Não há sinais de emagrecimento, embora a comida mal represente um décimo do regime habitual da paciente.

Conhecemos a força de resistência da saúde geral nas histéricas o suficiente para não estranharmos ver como suportam sem danos uma inanição sistemática, à qual mulheres robustas não se exporiam sem riscos. Além do mais, é necessário considerar que a diminuição dos alimentos acontece por graus e sem brusquidão; ora, a economia acostuma-se mais facilmente do que possa parecer a esse tipo de diminuição da alimentação. Todos comprovamos isso durante o Siége de Paris ${ }^{3}$ quando pudemos constatar como a dieta que os pobres tiveram de adotar não alterou, no início, fundamentalmente sua saúde.

Outro fato reconhecido é que em vez de diminuir as forças musculares, a redução de comida tende a aumentar a aptidão ao movimento. A paciente continua se sentindo mais ativa, mais leve, anda a cavalo, empreende longas caminhadas a pé, recebe e visita amigos e até, se for preciso, leva uma cansativa vida mundana, sem demonstrar os cansaços de que ter-se-ia queixado antigamente.

Não existem sinais visíveis de clorose ou anemia, ou pelo menos não se pode atribui-los à inanição, uma vez que a maioria dessas pacientes já eram mais ou menos cloro-anêmicas.

Se a situação não varia, no que diz respeito à anorexia e à recusa de alimentos, as disposições de seus familiares modificam-se à medida que a doença se prolonga e, junto com isso, o estado mental da histérica vai se agravando.

O médico, caso tenha prometido uma melhora rápida ou tenha suspeitado da má vontade da paciente, perdeu há muito sua autoridade moral. Entretanto, a paciente não recusa a administração de remédio algum. Assim como se mostra resistente quanto à comida, mostra-se dócil quanto a remédios, mesmo se não forem dos mais atraentes. Já vi umas abocanharem pedaços de ruibarbo, mas ninguém a convenceria a provar uma bisteca. Os mais ativos estimulantes gástricos, os purgativos benignos ou drásticos, as águas minerais digestivas

3. “Cerco de Paris”, quando Paris foi sitiada pelos alemães entre 19 de setembro de 1870 e 21 de janeiro de 1871 (NdT). 
permanecem sem o menor efeito. O mesmo se dá com chás estimulantes, gomas fétidas, valeriana, hidroterapia, duchas em temperaturas variadas, assim como fortificantes, ferruginosos, derivações cutâneas etc. Apenas os laxativos servem, por eliminarem a constipação; os outros agentes não propiciam nenhuma atenuação da anorexia.

Quando, após vários meses, a família, o médico, os amigos percebem a inutilidade persistente de todos seus esforços, a inquietação vai se impondo e com ela o tratamento moral. É nesse momento que vai se desenhar a perversão mental que, por si, é quase característica e justifica o nome que propus, por falta de opção melhor, de anorexia histérica.

A família só tem dois recursos à sua disposição que ela sempre esgota: rogar ou ameaçar. Ambos servem de pedra de toque. Multiplicam-se as iguarias à mesa, na esperança de despertar o apetite: quanto mais a solicitude aumenta, mais o apetite decresce. A doente prova desdenhosamente os novos pratos e após ter assim mostrado sua boa vontade, considera-se livre da obrigação de fazer mais do que isso. Suplica-se, reclama-se como um favor, como uma prova soberana de afeição que a paciente se resigne a acrescentar um único bocado suplementar a essa refeição que ela considera terminada. O excesso de insistência evoca um excesso de resistência. É uma lei muito conhecida e conforme à experiência de todos, essa de que o melhor meio para redobrar a teimosia das histéricas é o de deixar vir à tona a suposição implícita ou explicitamente expressa que se quisessem, poderiam dominar suas impulsões doentias. Uma simples concessão faria com que passassem do estado de doentes mentais ao de crianças mimadas, e a essa concessão, meio por instinto, meio por parti pris, elas nunca consentirão.

Gradualmente, a anorexia torna-se o único objetivo das preocupações e das conversas. Forma-se, assim, uma espécie de atmosfera em torno da paciente, que a envolve e da qual não escapa, em nenhum momento do dia. Aos parentes juntam-se os amigos e cada qual contribui para a obra comum em função da disposição de seu caráter ou grau de afeição. Ora, é uma lei não menos positiva essa de que a histeria se deixa levar por seu meio e que a doença aumenta ou se condensa à medida que o círculo no qual os sentimentos e as idéias da paciente evoluem vai se estreitando. A culpa não pode ser imputada apenas a um vício patológico do caráter. Diante da presença constante de sensações que lembram em muitos pontos as dos hipocondríacos e as idéias delirantes dos alienados, as histéricas não conseguem se subtrair a tal dominação por um esforço de vontade. Quando mais, conseguem esquecer por intervalos, quando se deixam distrair, sendo essa a única trégua que lhes é concedida. Quanto mais sua atenção se centraliza, mais a noção do mal-estar se aperfeiçoa. Passado um tempo variável nessa funesta concentração, a paciente entra numa nova fase, sua posição está 
definida, ela sistematiza, assim como certos alienados e não busca mais argumentos: as respostas tornam-se mais uniformes ainda do que as perguntas.

Entretanto, e para todos que já foram envolvidos nesse tipo de cenas dolorosas de família, não acharão o quadro detalhado ou sombrio demais: os suplicantes se cansam e passam a exigir. Nova tentativa, mais infrutífera do que as precedentes.

De fato, dizer o quê? Que a doente não pode viver com uma quantidade de alimentos que não bastaria para uma criança de baixa idade? Ela responde que sua alimentação lhe basta e que, além do mais, não mudou ou emagreceu e nunca se recusou a uma tarefa ou trabalho cansativo; ela, melhor do que qualquer outro, é quem sabe do que precisa e, além do mais, não toleraria uma alimentação mais abundante.

Que a inanição acabará provocando uma doença estomacal com o tempo? A histérica responde que nunca se sentiu tão bem, que não sente sofrimentos e que esses receios são desmentidos por seu bem-estar.

Nesse estágio, as dores do começo já se dissiparam ou se atenuaram, e quando reaparecem, é apenas em intervalos longínquos, ou em proporções facilmente toleráveis. Mais um argumento em favor desse regime ao qual o estado de saúde da paciente paga um tributo.

O jejum, por sinal, não é absoluto e nada tem em comum com a recusa de alimentação dos melancólicos. A anorexia não piorou e essencialmente não se transformou numa repulsão análoga àquela sentida pelos tísicos e muitos cancerosos. A doente assiste com prazer às refeições da família, contanto que a deixem comer segundo sua vontade.

O que domina no estado mental da histérica é, antes de mais nada, uma quietude, diria quase um contentamento verdadeiramente patológico. Não apenas ela não lamenta a falta de cura, mas se compraz em sua condição, apesar de tantas contrariedades que essa lhe suscita. Ao comparar essa segurança satisfeita com a obstinação do alienado, não acredito estar exagerando. Se colocássemos todas as anorexias em perspectiva, veríamos o quanto diferem entre si. Mesmo no ponto máximo de suas repugnâncias, o canceroso espera e solicita um alimento que desperte seu apetite. Ele está disposto a todas as tentativas embora não consiga vencer sua aversão. O dispéptico sem lesão orgânica esforça-se por variar seu regime, por ajudar a si mesmo de qualquer forma e se queixa com o azedume habitual de quem sofre do estômago. Nada disso no caso que evocamos, pelo contrário: um otimismo inexpugnável que todas as suplicações e ameaças não conseguem abalar. Não sofro, portanto estou bem de saúde, essa é a fórmula monótona que substituiu a antiga: não posso comer porque sofro. Já ouvi tantas pacientes repeti-la, que, para mim, ela já representa um sintoma, quase um sinal. 
Se confiro ao estado mental uma importância que pode parecer exagerada, é porque a doença por inteiro se resume a essa perversão intelectual: se a suprimirmos, obteremos uma afecção banal fadada a ceder, com o tempo, aos processos clássicos de tratamento; se a levarmos a seu paroxismo, nunca iremos mais adiante; teremos uma dispepsia sem paridade com as outras, que segue um curso previsto e não poderia ser conjurada pelos meios habituais.

Não acredito que a histeria gástrica seja uma exceção nesse aspecto: nas outras localizações histéricas reencontramos pelo menos uma indiferença igual, por mais incômodos ou penosos que seus acidentes possam parecer. A histérica com tosse compulsiva não insiste para ser livrada de um espasmo irritante e às vezes ridículo: suas queixas fazem eco àquelas de quem sente dó dela, mas quando se trata de lutar ativamente contra o mal, ela confere a seu tratamento mais despreocupação do que zelo. O mesmo se dá com os paraplégicos condenados ao repouso absoluto, que se resignam a essa vida sem exigir do médico, cansados por tentativas inúteis, que recorra a métodos heróicos.

Junto com dois colegas, observei um caso raro e que ilustra bem a característica que busco ressaltar. Tratava-se de uma moça de 20 anos, acometida por uma dor da laringe, espasmódica ou outra, consecutiva a exercícios de canto. A dor, se é que a sensação presente merecia esse nome, era indecisa, inexplicável, mas particularmente incômoda; a paciente começou por parar de cantar, de maneira obstinada e sem querer nem se submeter a novas experiências, que declarava de antemão estarem acima de suas forças. Seu desejo mais caro era o de se tratar, contanto que não se exigisse mais nenhum esforço dela. Os mais racionais tratamentos permaneceram sem efeito. O mal-estar continuou por um ano aproximadamente.

Os mesmos fenômenos semi-dolorosos tornaram a se produzir, tão vagos quanto desalentadores, não mais ao cantar, dessa feita, mas pelo simples ato de falar. A paciente condenou-se a um mutismo completo, preferindo escrever numa caderneta a articular uma palavra sequer. Ela confinou-se assim num isolamento voluntário que suprimiu todas as relações com seus próximos e com o mundo. Ela escrevia, em meio a seus pensamentos, que sua situação lhe parecia intolerável; ela nunca recusou qualquer medicação, mas era incapaz de se decidir a falar apesar da pressão persistente de seus próximos. Instada quanto à natureza do obstáculo diante do qual recuava, ela respondia que o sofrimento nada tinha de enorme, mas achava não ter forças para enfrentá-lo. Quando, numa rara condescendência, articulava uma ou outra palavra, sua voz era sonora, bem empostada e não acusava a menor lesão; por sinal, sua laringe, cuidadosamente examinada, estava completamente sã.

Ora, as oportunidades de se observar pacientes afônicos, roucos, incapazes de falar, apesar de não sentirem qualquer sofrimento são tão freqüentes quanto 
as de ver dispépticos com anorexia. Será que essa particularidade que acabo de mencionar é encontrável, uma única vez que seja, fora dos estados histéricos, com a conservação completa da voz e a repugnância não menos completa a proporcionar a ocasião de um mal-estar que parece absolutamente local?

Também vi, em jovens histéricas numa época mais próxima à puberdade, o mesmo poder de inércia recair sobre outras funções. Numa paciente de 16 anos, que já passara por vários ataques clônicos, o andar e até mesmo ficar em pé, provocavam, segundo ela, sensações dolorosas nos membros inferiores e um mal-estar indefinido; não se conseguia determinar qualquer enfraquecimento muscular.

No entanto, a moça começou por restringir seus movimentos e mal saía da cama para dar alguns passos; mais tarde, só consentiria em se deixar levar de sua cama até uma poltrona onde ficaria sentada durante algumas horas; mais tarde ainda, condenou-se a um decúbito absoluto dia e noite. Isso durou mais de dezoito meses.

Nesse caso, ao contrário da fonação e da alimentação, podia-se recorrer a uma espécie de ginástica passiva, levantar a paciente, mantê-la em pé, fazer com que andasse com apoio. A experiência foi repetida um sem número de vezes, sempre sem o menor êxito. A família estava preocupada, apesar das mais firmes garantias em contrário, e pensava em paralisia; alguns médicos duvidaram, diante da persistência do mal, de sua natureza histérica. A criança persistiu durante todo aquele tempo e só se curou através de uma lenta melhora atribuída a banhos de mar quentes.

Na histeria, na hipocondria, num grande número de afecções do sistema nervoso central, podemos constatar apreensões sem proporção com a dor. À primeira vista, esse fato explica-se pelo que se denomina de suscetibilidade exagerada; admite-se que o paciente amplia desmedidamente a importância do mal e que se inquieta em virtude de uma concepção teórica. A supor que isso seja verdadeiro, estaríamos, mesmo assim, diante de uma aptidão mental patológica, reservada aos doentes imaginários; as coisas, contudo, ocorrem de modo diferente. Cada sensação local é acompanhada por um mal-estar geral, uma perturbação impossível de se descrever, um sentimento de colapso, de fraqueza; mal-estar que não oferece parâmetros para avaliar seu valor e se torna mais penoso com o aumento da confusão. Todos já sentimos essa sensação no início de uma indigestão, como preliminar a um vômito ou como começo de uma doença nascente.

A verdade é que o mal-estar estomacal das histéricas não se resolve numa simples gastralgia, mas faz parte de um conjunto de sintomas inquietantes. A prova disso é que, após a administração de algum medicamento, embora o estômago esteja irritado, dolorido, o paciente não confunde essa dor, por assim 
dizer artificial, com as que estava sentindo antes. Esse é o caráter dos sofrimentos reflexos e, mencionado isso, não quero me estender demais sobre a descrição do fenômeno.

Durante esse segundo período, assim constituído: falta de apetência, receio de uma sensação indefinida, recusa absoluta e crescente de se prestar às tentativas de alimentação, a doença permanece estável. A obstinação persiste por meses, quando não por anos. Num caso em que tomei, enquanto médico, a sucessão de um de nossos mestres, a paciente recebera cuidados assíduos durante dezoito meses e, com essa indolência mesclada de uma ponta de causticidade, repetia a conversação que ocorria duas vezes ao dia, entre ela e seu médico:

— E aí minha filha, decidiu comer?

- Doutor, fiz o melhor que pude, mas não consegui.

- Mais um esforço, e tudo vai dar certo.

No fim, a tolerância da economia, por mais maravilhosa que seja nas histéricas, acaba por esgotar-se e a paciente entra no terceiro estágio.

As menstruações até então insuficientes, irregulares, não ocorrem mais, e a sede aparece. Esses são, via de regra, os primeiros sinais de complicações iminentes. O exame objetivo deixa aparecer uma retração das paredes abdominais até então inexistente; a apalpação indica uma diminuição progressiva da elasticidade, habitual em casos de inanição prolongada. A região epigástrica tornou-se dolorosa à pressão, embora a doente não se queixe de dores espontâneas. A constipação persistente não responde mais aos purgativos. A pele está ressecada, rugosa, sem agilidade, o pulso freqüente.

$\mathrm{O}$ emagrecimento começa a progredir rapidamente e com ele a fraqueza geral. O exercício torna-se laborioso e a paciente permanece de bom grado em decúbito; quando se levanta, sente vertigens, uma tendência à indisposição, ou, ainda, crises de síncope. O rosto está pálido, sem que lábios estejam descoloridos. Um barulho de sopro cardio-vascular, de causa anêmica, quase constante, está presente e, em geral, chega antes da afecção, e raramente deixa de estar presente nos estados adiantados. Este quadro está longe de representar exatamente as diversidades individuais que costumam ser observadas. Ora o emagrecimento domina, ora é a fraqueza, ou ainda o estado anêmico com seu cortejo de acidentes localizados ou generalizados. Excepcionalmente, distúrbios nervosos espasmódicos, neuralgias etc. podem surgir. Os sintomas ativos parecem apagarse à medida que a força de resistência vital vai diminuindo.

Com o aparecimento desses sinais, cuja gravidade não escapa a ninguém, as inquietações redobram: amigos e parentes tendem a considerar a situação como desesperada. Não se espantem ao ver-me, ao contrário de nossos hábitos, estabelecer um paralelo constante entre o estado mórbido da histérica e as preocupações de seus próximos. Ambos os termos são solidários e obter-se-ia 
uma noção errônea da doença ao limitarmos o exame à doente. A partir do momento em que intervém um elemento moral, cuja existência é aqui indubitável, o meio em que vive a paciente exerce uma influência que seria igualmente lamentável ignorar ou desconhecer. À aflição verdadeira, sincera, sucederam as reprimendas: pela força dos sentimentos tanto quanto das necessidades inspiradas pelos novos mal-estares, a histérica foi elevada ao estatuto de doente, ela não pertence mais ao livre movimento da vida comum.

Essa mudança inconsciente nas posições respectivas da paciente e de seus familiares pareceu-me desempenhar um papel importante. A moça começa a inquietar-se com o aparato entristecido que a rodeia e, pela primeira vez, sua indiferença satisfeita se desconcerta: este é o momento em que o médico poderá retomar sua autoridade, caso tenha tido o cuidado de resguardá-la para o futuro; o tratamento não é mais aceito com uma condescendência passiva, mas acolhido com uma apetência que a paciente procura disfarçar. A luta que se estabelece entre o passado e o presente tem uma história estranha, mas é fácil de constatar, contanto que se consiga nada deixar transparecer dessa investigação.

Duas direções descortinam-se, então, diante da paciente: ou ela consegue relaxar o suficiente para se tornar obediente sem restrição, e esse é o caso mais raro, ou passa para um estado de semi-docilidade na esperança evidente de que conjurará o perigo sem renunciar às suas idéias e talvez ao interesse que sua doença desperta. Essa segunda tendência, de longe a mais comum, complica muitíssimo a situação. Restabelecer o funcionamento regular de um estômago condenado por tanto tempo ao repouso não é tarefa fácil: passa-se por sucessos e fracassos alternados e, em geral, não se obtém senão um resultado insuficiente. Conheço pacientes que não recuperaram a aptidão de se alimentar como todo mundo, dez anos após o começo de sua doença; elas estão vivas, sua saúde não está profundamente afetada, mas essa melhora está longe de qualquer cura.

Às vezes, um acontecimento inesperado vem quebrar o curso da doença, um casamento, um pesar, uma perturbação moral profunda. Outras vezes, será um incidente físico, uma gravidez, uma afecção febril; mas há quem resista a essas duas ordens de poderosos modificadores.

Via de regra, há de se prever que a mudança para melhor operar-se-á lentamente, por abalos sucessivos, mas não se pode predizer o quanto de melhora será suficiente.

Por mais fundamentadas que as inquietudes sejam, ainda não vi caso de anorexia com desfecho mortal, embora, apesar dessa certeza experimental, já tenha passado por repetidas perplexidades. Ocorre, provavelmente, que a sensação patológica, causa primeira da anorexia, acabe desaparecendo por causa da crescente caquexia. Não apenas a febre, como vários outros estados doentios, resolvem os espasmos. Livre de sua preocupação sub-delirante, a histérica adota 
a condição de qualquer dispéptico e não oferece outras dificuldades que não as habituais. A histeria em si, por mais violenta que possa ser, não é mortal, embora seja a causa ocasional, ou indireta, por assim dizer, de doenças com desfecho fatal, entre as quais a tuberculosização pulmonar. Em uma única oportunidade, numa mulher casada de 30 anos, histérica de longa data, consegui ver a transformação que acabo de mencionar. A repugnância por comida surgira por causa de pesares mais imaginários do que reais, embora profundamente sentidos, e minhas primeiras suspeitas foram as de que se tratava de uma tentativa de suicídio dissimulada. O decorrer do caso logo me levou a afastar essa suposição e a doente faria, tarde demais, esforços verdadeiros para apegar-se à vida.

As histéricas sempre se curaram mais ou menos completamente após alguns anos e passaram, nos anos de declínio, por períodos de apetites limitados, ou mesmo exclusivos e, às vezes, estranhos. Junto com Trousseau, cuidei de uma moça fundamentalmente histérica, desde a idade púbere, que fora acometida por uma invencível anorexia sem causa identificável. A doença chegara a um estado de emaciamento e fraqueza tal que ela não conseguia mais sair da cama. Sua alimentação limitava-se exclusivamente a algumas xícaras de chá com um pouco de leite. A constipação persistente provocara uma diarréia com exsudatos pseudomembranosos. Isso não impediu que ficasse grávida, e sob a influência dessa gravidez, ela se esforçou para encontrar uma alimentação que seu estômago aceitasse. Durante seis meses, ela apenas se alimentou com café com leite, no qual ela molhava, à guisa de pão, pepinos de picles; aos poucos, embora muito lentamente, acrescentou algumas féculas a esse regime singular. Hoje em dia, ela se encontra num estado de saúde dos mais satisfatórios, apesar de uma magreza excessiva.

Na maioria das vezes, o apetite limita-se a alimentos escolhidos de modo menos bizarro e é nesse momento que se dá livre curso à fantasia. Lembro-me de uma paciente de 26 anos, solteira, que morava numa província afastada e se recusava a comer outra coisa que não bolachas sem açúcar, preparadas por certo confeiteiro de Paris; outras se limitavam a um único tipo de legumes e recusavam carne e pão; outras, ainda, só consentiam comer pratos cujo gosto fosse dissimulado por especiarias.

Embora essas restrições caprichosas sejam um sinal favorável, as doentes continuam a enfrentar a comida que escolheram sem apetência, por falta de escolha melhor. A anorexia persiste por tempo indefinido muito após elas voltarem a um regime normal. Nunca vi casos de recidiva; uma vez estabelecida, a cura se mantém. Na época em que a afecção histérica cedera ou revestira outras formas, solicitei informações mais precisas das pacientes, quanto às sensações que sentiam e que as afastaram dos alimentos: nenhuma me forneceu, nessa investigação retrospectiva, informações outras que não as que aqui mencionei. 
Era sempre essa fórmula típica, igual à dos períodos de afecção, que voltava: "não conseguia, era mais forte do que eu e, além do mais, estava passando bem”.

Esta dissertação tomou por base 8 observações, todas relativas a mulheres entre 18 e 32 anos. A histeria expressara-se, nelas, na forma dos mais diversos sintomas: uma, cloro-anêmica, não tivera crises, mas sua mãe sofrera, além de muitas crises, dois surtos de hemiplegia histérica.

Era bastante fácil atribuir uma data de início, a anorexia se perdia por degradações tão imperceptíveis que não se poderia situar seu fim com precisão. Para permenecermos o mais perto possível da verdade, podemos dizer que a afecção, com as fases que mencionei, nunca durou menos de dezoito meses a dois anos.

Embora os fatos fossem, na realidade, pouco numerosos, apresentavam entre si uma semelhança tal que os últimos casos não deixaram margem para indecisão tanto no diagnóstico quanto no prognóstico, e que de fato tudo correu conforme a regra. Ao descrever essa variedade, meu propósito, como dizia no começo, era o de ressaltar uma espécie, ou um fragmento, mas sobretudo assinalar o papel fundamental desempenhado, em certas formas de histeria, pela disposição mental das pacientes e de mostrar, mais uma vez, a relação íntima entre a histeria e a hipocondria. 